\begin{tabular}{l} 
UADESIS \\
Universitas \\
Ahmad Dahlan \\
VOL. 3. No. 1, Januari 2022 \\
\hline
\end{tabular}

\title{
SARKASME DI KALANGAN SANTRI PERSADA UNIVERSITAS AHMAD DAHLAN
}

\author{
Chika Ardeviya Rista \\ Alumni Program Studi Sastra Indonesia Universitas Ahmad Dahlan \\ chikaardeviyarista22@gmail.com \\ Intan Rawit Sapanti \\ Program Studi Sastra Indonesia Universitas Ahmad Dahlan \\ intanrawit.sapanti@idlitera.uad.ac.id
}

\section{ARTICLE INFO}

ABSTRACT

Article history

Received 20 October 2021

Revised 29 Jnauary 2022

Accepted 29 January 2022

Keywords

Sarcasm

Santri

Persada UAD

Sociolinguistics
This research is motivated by the importance of understanding the forms of sarcasm uttered by students so that the public knows the purpose of using sarcasm. The problems discussed in this study are (1) the form of sarcasm used by Persada UAD 2019/2020 students based on grammar, (2) the form of sarcasm used by Persada UAD 2019/2020 students based on the content of the speech, and (3) the factors causing Persada UAD students to use the form of sarcasm. This study aims to describe the form of sarcasm among Persada UAD students and find out the factors causing Persada students to use sarcasm among Persada UAD students. Based on the research results regarding the form of using sarcasm by Persada UAD students in 2019/2020, the following conclusions were obtained. (1) The use of sarcasm among the students of Persada UAD in 2019/2020 based on the grammatical basis was found in three forms, namely words, phrases, and clauses. (2) The use of forms of sarcasm among Persada UAD students in 2019/2020 based on the content of the speech found seven forms of sarcasm, namely words containing bitterness, bitter reproaches, expressions of anger, swearing, words that are not pleasant to hear, ridicule, and certain social varieties. (3) The factors causing the students of Persada UAD in 2019/2020 to throw sarcasm found ten factors, namely social background, habits, reflexes, anger, inappropriate place and time, inappropriate participants, goals that did not match the speaker, tone when conveying messages, media language, and norms in interaction.

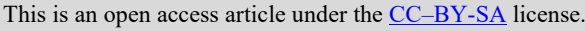

\section{Article history}

Received 20 Oktober 2021

Revised 29 Januari 2022

Accepted 29 Januari 2022

Keywords

Sarkasme

Santri

Persada UAD

Sosiolinguistik
Penelitian ini dilatarbelakangi oleh pentingnya pemahaman tentang bentuk sarkasme yang dilontarkan santri agar masyarakat mengetahui maksud dari penggunaan sarkasme. Masalah yang dibahas dalam penelitian ini adalah (1) bentuk penggunaan bahasa sarkasme yang dilontarkan oleh santri Persada UAD 2019/2020 berdasarkan gramatikal, (2) bentuk penggunaan bahasa sarkasme yang dilontarkan oleh santri Persada UAD 2019/2020 berdasarkan isi tuturan, dan (3) faktor penyebab santri Persada UAD menggunakan bentuk sarkasme. Penelitian ini bertujuan untuk mendeskripsikan bentuk penggunaan sarkasme di kalangan santri Persada UAD, dan mengetahui faktor penyebab santri Persada melontarkan bentuk sarkasme di kalangan santri Persada UAD. Berdasarkan hasil penelitian mengenai bentuk penggunaan sarkasme yang dilontarkan santri Persada UAD tahun 2019/2020 diperoleh kesimpulan sebagai berikut. (1) Penggunaan bentuk sarkasme di kalangan santri Persada UAD tahun 2019/2020 berdasarkan gramatikal ditemukan sebanyak tiga bentuk yaitu kata, frasa, dan klausa. (2) Penggunaan bentuk sarkasme di kalangan santri Persada UAD tahun 2019/2020 berdasarkan isi tuturan ditemukan tujuh bentuk sarkasme yaitu kata yang mengandung kepahitan, celaan getir, ungkapan kemarahan, umpatan, kata yang kurang enak di dengar, cemoohan, dan ragam sosial khusus. (3) Faktor penyebab santri Persada UAD tahun 2019/2020 melontarkan sarkasme ditemukan sepuluh faktor yaitu latar belakang pergaulan, kebiasaan, reflek, marah, tempat dan waktu tidak tepat, partisipan tidak tepat, tujuan tidak sesuai dengan penutur, nada saat menyampaikan pesan, media bahasa, dan norma dalam berinteraksi. 


\section{PENDAHULUAN}

Sarkasme menurut Keraf (2005:143) memiliki arti "berbicara dengan kepahitan" sehingga kata-kata yang digunakan cenderung akan dapat menyakiti hati lawan bicaranya karena kurang enak didengar. Fenomena budaya Islami yang menjadi ciri khas pesantren bagi sebagian orang awam menjadikan santri yang selalu identik dengan kesan islami, mulai dari pakaian hingga gaya berbicara terkesan kental dengan adab dan akhlak Islami. Namun tidak dapat dipungkiri bahwa banyak mahasantri di Persada UAD yang menggunakan bentuk sarkasme. Bentuk sarkasme cenderung menggunakan bahasa daerah setempat dan berkembang hingga wilayah lain, bersamaan dengan berpindahnya penutur, sehingga mengalami persebaran dan mulai dianggap sebagai hal biasa. Sebagai contoh, bentuk sarkasme orang Jawa dengan mengatakan umpatan asu. Ketika penutur dari Jawa berpindah ke wilayah lain tidak dapat dipungkiri bahasa sarkasme tersebut akan diucapkannya entah karena spontanitas atau memang dengan sengaja.

Penggunaan bentuk sarkasme terkadang tidak hanya untuk umpatan saja, namun sarkasme sendiri dapat berfungsi sebagai rasa keakraban pada suatu kelompok masyarakat. Bahkan sarkasme menjadi humor tersendiri bagi sebagian orang untuk selingan dari rutinitas agar tidak tegang, sehingga fungsi sarkasme bukan hanya menyakiti hati orang lain saja baik sengaja maupun tidak sengaja. Mungkin saja jika orang awam yang mendengar kata sarkasme yang dilontarkan dapat menimbulkan kesan negatif. Bahasa tentu tidak dapat terlepas dari budaya dan sosial lingkungan penuturnya. Hal ini sesuai dengan konsep dalam sosiolinguistik yang dikemukakan oleh Fishman (1972) dalam Chaer (2014:15) "who speak what language tho whom, when and to what end". Oleh karena itu, fungsi bahasa antara lain dapat dilihat dari sudut penutur, pendengar, topik, kode, dan amanat pembicaraan.

Sosiolinguistik merupakan ilmu yang mempelajari ciri dan pelbagai variasi bahasa, serta hubungan di antara para bahasawan dengan ciri fungsi variasi bahasa itu di dalam suatu masyarakat bahasa (Kridalaksana 1978:94). Fishman (Chaer, 2014:5) menyatakan bahwa sosiolinguistik berhubungan dengan perincian-perincian penggunaan bahasa yang sebenarnya, seperti deskripsi pola-pola pemakaian bahasa atau dialek dalam budaya tertentu, pilihan pemakaian bahasa atau dialek tertentu yang dilakukan penutur, topik, dan latar pembicaraan. Bidang sosiolinguistik termasuk ke dalam makrolinguistik, artinya mempelajari hal eksternal yang berkaitan dengan linguistik. Sosiolinguistik memfokuskan pada penelitian variasi bahasa ujaran, serta mengkajinya dalam konteks sosial.

Ungkapan kasar lebih banyak terjadi pada situasi nonformal. Berdasarkan tingkat keformalannya, Martin Joos dalam Chaer dan Agustina (2014: 70) membagi variasi bahasa menjadi lima yaitu: 1. Ragam Beku (frozen) merupakan variasi bahasa yang biasnya digunakan dalam situasi-situasi khidmat, upacara-upacara resmi, seperti khutbah, upacara kenegaraan, dan lain-lain. Disebut ragam beku karena pola dan kaidahnya sudah ditetapkan secara mantap dan tidak boleh diubah. Ragam bentuk baku dalam bentuk tertulis dapat ditemui pada dokumen bersejarah, seperti undang-undang dasar, akta notaris, naskah-naskah perjanjian jual beli, dan lain-lain; 2. Ragam Resmi (formal) merupakan variasi bahasa yang biasanya digunakan dalam pidato kenegaraan, rapat dinas, buku-buku pelajaran, dan lain-lain. Ragam ini digunakan pada situasi resmi saja; 3. Ragam Usaha (konsultatif) merupalan variasi bahasa ini digunakan dalam pembicaraan biasa seperti di sekolah dan rapat-rapat atau pembicaraan yang berorientasi kepada hasil atau produksi. Wujud variasi ini berada di antara ragam formal dan ragam informal atau santai; 4. Ragam Santai (casual) merupakan variasi bahasa ini digunakan dalam situasi tidak resmi sekadar untuk berbincang-bincang dengan keluarga atau teman karib pada waktu istirahat, berekreasi, dan sebagainya. Ragam santai ini lebih banyak menggunakan 


\begin{tabular}{l} 
UADESIS \\
Universitas \\
Ahmad Dahlan \\
VOL. No. 1, Januari 2022 \\
\hline
\end{tabular}

bentuk alegro berupa kata atau ujaran yang dipendekan. Kosa katanya banyak dipenuhi unsur leksikal dialek dan unsur bahasa daerah; 5. Ragam Akrab (intimate) merupakan variasi bahasa ini biasanya digunakan oleh penutur yang hubungannya sudah akrab, seperti antar anggota keluarga, antarteman yang sudah karib. Ragam ini ditandai dengan penggunaan bahasa yang tidak lengkap, pendek-pendek dan dengan artikulasi yang sering tidak jelas.

Bentuk sarkasme dikaitkan dengan faktor-faktor yang mempengaruhi santri dalam berkata sarkasme dapat ditinjau menggunakan teori Dell Hymes. Peristiwa tutur harus memenuhi delapan komponen yang bila huruf-huruf pertamanya dirangkai menjadi akronim SPEAKING (diangkat dari Wadhaugh 1090) dalam Chaer (2014:48). Kedelapan komponen itu adalah sebagai berikut. 1. Setting and scene; 2. Participants; 3. End; 4. Act Sequences; 5. Key; 6. Instrumentatie; 7. Norms of interaction and interpretation; 8. Genres. Penggunaan bentuk sarkasme yang dilontarkan oleh santri Persada menjadi salah satu bentuk variasi bahasa dalam segi keformalan.

Penelitian ini bertujuan untuk menganalisis lebih dalam mengenai bentuk bahasa sarkasme serta faktor yang menyebabkan santri melontarkan bahasa sarkasme di lingkungan santri Persada sebagai pesantren mahasiswa yang identik dengan budaya islami. Penelitian ini mengambil data penelitian di lingkungan pesantren dan data-data tersebut menjadi sedemikian kompleks karena penghuni pesantren berasal dari berbagai wilayah di Indonesia.

\section{METODE}

Metode pengumpulan data pada penelitian ini menggunakan metode simak. Metode ini hampir sama dengan metode pengamatan atau metode observasi. Metode simak adalah suatu pemerolehan data yang dilakukan dengan cara menyimak suatu penggunaan bahasa (Mahsun, 2005: 90). Metode simak dilakukan dengan mengumpulkan data melalui proses penyimakan dan pengamatan terhadap penggunaan bahasa yang akan diteliti. Setelah melakukan metode simak dilanjutkan dengan metode baca dan catat. Metode catat dapat dilakukan bersamaan dengan metode simak. Pencatatan data dilakukan pada kartu data yang sesuai dengan objek penelitian.

Metode dan teknik analisis data menggunakan metode padan. Metode padan merupakan metode yang alat penentunya di luar, terlepas, dan tidak menjadi bagian dari bahasa yang bersangkutan (Sudaryanto, 1993:13). Metode ini digunakan untuk menentukan identitas satuan lingual tertentu dengan menggunakan alat penentu dari luar bahasa yang bersangkutan. Berdasarkan alat penentu berupa kenyataan yang ditunjuk oleh bahasa, penelitian ini menggunakan metode padan referensial. Referen bahasa adalah benda, tindakan, sifat, keadaan, jumlah, dsb yang mengacu kepada dunia nyata kehidupan manusia (Zaim, 2014:99).

\section{PEMBAHASAN}

\section{a. Budaya Pesantren}

Institusi pesantren diartikan sebagai lembaga pendidikan Islam yang memiliki pondok, masjid, santri, pengajaran kitab-kitab Islam klasik, dan kyai merupakan lembaga gabungan antara sistem pondok dan pesantren (tradisional) dan dilengkapi dengan pendidikan formal berbentuk madrasah, bahkan sekolah umum dalam pelbagai bentuk dan tingkatan dan aneka kejuruan menurut kebutuhan masyarakat masing-masing (Shaleh, 2000:118). Dalam dunia pesantren tentunya pendidikan akhlak sangat penting. Pendidikan akhlak merupakan pendidikan inti yang dilandasai ajaran Nabi Muhammad saw sesuai dengan sabda beliau sebagai berikut: 


\begin{tabular}{l} 
UADESIS \\
Universitas \\
Ahmad Dahlan \\
VOL. No. 1, Januari 2022 \\
\hline
\end{tabular}

انما بعثت لاتمم مكرم الاخلاق

Artinya: "Sesungguhnya aku diutus untuk menyempurnakan akhlak" (HR. Ahmad) (Yusuf, 2003:175).

Pendidikan pesantren menurut Ali dalam Haedari (2004: 15) memiliki identifikasi sebagai berikut. (1) adanya hubungan yang akrab antara kyai dan santri, (2) tradisi ketundukan dan kepatuhan seseorang, (3) pola dan hidup sederhana (zuhud), (4) kemandirian, (5) berkembangnya iklim dan tradisi tolong menolong dan suasana persaudaraan, (6) disiplin ketat, (7) berani menderita untuk mencapai tujuan, (8) kehidupan dengan tingkat religiusitas yang tinggi. Pendidikan karakter santri menjadi poin penting dari pendidikan pesantren. Sesuai dengan UU No. 20 Tahun 2003 mengenai Sistem pendidikan nasional Pasal 3 yang berbunyi bahwa pendidikan nasional berfungsi membangun kemampuan dan membentuk watak serta peradaban bangsa yang bermartabat dalam rangka mencerdaskan kehidupan bangsa, bertujuan untuk berkembangnya potensi peserta didik agar menjadi manusia yang beriman dan bertakwa kepada Tuhan Yang Maha Esa (YME), berakhlak mulia, sehat, berilmu, cakap, kreatif, mandiri, dan menjadi warga negara yang demokratis serta bertanggung jawab (UU. SISDIKNAS No. 20 Tahun 2003). Pesantren memiliki peranan penting dalam menanam karakter bidang keilmuan, bidang akhlak, dan bidang sosial dalam diri santri.

\section{1) Karakter Santri di Bidang Keilmuan}

Pesantren sebagai lembaga pendidikan memiliki peranan penting dalam melakukan proses belajar mengajar. Pembelajaran pesantren menurut Haedari (2004: 17-21) membaginya menjadi Hafalan (Tahfizh), Hiwar/Musyawarah, Mudzakaroh, Fathul Kutub, Muqoronah (perbandingan), Munawarah/ Muhadatsah (latihan bercakap/pidato). Di beberapa pesantren menganjurkan santrinya mempelajari ilmu Nahwu saraf hingga dapat fasih dalam membaca kitab gundul. Ilmu-ilmu tersebut diberikan oleh ustaz, ustazah, guru, Kyai, serta buku referensi. Literatur yang baik akan berbagai pelajaran yang diberikan di pesantren membuat santri terbangun karakter dalam bidang keilmuan yang kuat.

\section{2) Karakter Santri di Bidang Akhlak}

Akhlak menjadi pembelajaran utama yang ditekankan oleh pesantren. Inti dari pembelajaran agar santri memiliki akhlakul karimah. Berakhlakul karimah yaitu berakhlak kepada Allah swt, berakhlak kepada sesama, dan berakhlak kepada lingkungan (Yusuf, 2003: 178-191). Berakhlakul karimah kepada Allah swt dicerminkan dengan meningkatkan iman, takwa, tauhid, dan amal saleh. Akhlak terhadap sesama makhluk dengan senantiasa berbuat baik dan berperilaku terpuji. Akhlak kepada lingkungan dengan menanamkan pada diri santri agar menyayangi serta melakukan hal-hal yang berkenaan dengan kemaslahatan umat.

\section{3) Karakter Santri di Bidang Sosial}

Santri sebagai bagian dari makhluk sosial tentu tidak dapat lepas dengan aktivitas sosial masyarakat lainnya. Pesantren berperan penting dalam menanamkan nilai-nilai moral yang mampu membentuk karakter santri terutama dalam bidang sosial. Nilai-nilai empati, peduli, toleransi, dan gotong royong menjadi nilai-nilai moral yang mencerminakan perilaku terpuji dan akhlakul karimah. 


\begin{tabular}{l} 
UADESIS \\
Universitas \\
Ahmad Dahlan \\
VOL. No. 1, Januari 2022 \\
\hline
\end{tabular}

\section{b. Sejarah Persada UAD}

Pesantren Mahasiswa KH. Ahmad Dahlan (Persada) Yogyakarta awalnya diberi nama Graha Ahmad Dahlan (Grahada). Berbentuk gedung kembar dengan lima lantai yang didirikan pada tahun 2009. Lahan seluas 2 Ha yang dibangun menjadi Rumah Susun Sederhana Sewa (Rusunawa) merupakan hibah dari pemerintah kepada Universitas swasta sebagai hunian mahasiswa. Kemudian oleh Pimpinan UAD digunakan sebagai wadah pembinaan akademik dan moral agar manfaatnya jauh lebih besar ketimbang hanya dijadikan hunian saja.

Latar belakang daerah santri yang berbeda-beda menjadikan adanya perkembangan sosial, budaya, dan bahasa. Tidak terkecuali bentuk sarkasme yang dewasa ini sedang menjadi trend di kalangan kaum muda. Mahasiswa yang pada dasarnya berusia remaja gemar mengeksplorasi sesuatu yang baru. Bahasa menjadi salah satu yang dieksplor oleh mahasiswa walaupun terkesan melanggar kaidah bahasa. Begitupula dengan santri yang notabennya kaum muda meski berada di lingkungan Persada yang agamis tidak dapat dipungkiri adanya penggunaan sarkasme. Pergaulan di luar Persada menjadi tolak ukur perkembangan sarkasme di kalangan santri meski identik dengan agamis. Penggunaan bentuk sarkasme yang dilontarkan hanya agar terlihat keren ataupun dapat diterima di kelompok tertentu.

\section{c. Sarkasme di Persada UAD}

Penggunaan bentuk sarkasme berdasarkan gramatikal. Bentuk sarkasme yang terdapat dalam 63 peristiwa tutur ditemukan sebanyak 70 data. Bentuk sarkasme secara gramatikal yang ditemukan berupa kata, frasa, dan klausa. Bentuk sarkasme secara gramatikal dapat diklasifikasikan sebagai berikut.

Tabel 1. Bentuk Sarkasme secara Gramatikal

\begin{tabular}{|c|c|c|c|c|}
\hline No & $\begin{array}{l}\text { Bentuk } \\
\text { Sarkasme } \\
\text { secara } \\
\text { Gramatikal }\end{array}$ & Contoh Data & Kode Data & $\begin{array}{c}\text { Jumlah Data } \\
\text { yang } \\
\text { ditemukan }\end{array}$ \\
\hline 1. & Kata & $\begin{array}{l}\text { p:“Sialan emang dia tuh" } \\
\text { q: "Kenapa lagi?" } \\
\text { p: "Pinjem sandal kagak bilang". }\end{array}$ & $\begin{array}{l}3,4,6,7,8,9,10 \mathrm{~b}, 11, \\
12,14,15 \mathrm{~b}, 18,19,21, \\
26,28 \mathrm{a}, 29 \mathrm{a}, 29 \mathrm{~b}, 31 \mathrm{a}, \\
31 \mathrm{~b}, 32,33,34,36, \\
39,40,41,42,44,45, \\
47,49,51,52,53,56, \\
57,58,59,61,63 .\end{array}$ & 41 \\
\hline 2. & Frasa & $\begin{array}{l}\text { p : "Eh lu, dipanggilin kagak denger } \\
\text { po?" } \\
\text { q : "Kagak, aku pake headset soalnya". } \\
\text { p : "Dasar budeg" }\end{array}$ & $\begin{array}{l}1,5,10 \mathrm{a}, 13,15 \mathrm{a}, 16 \\
17 \mathrm{a}, 20,24 \mathrm{~b}, 25,27 \\
28 \mathrm{a}, 30,35,37,38 \\
43,50,54,62\end{array}$ & 20 \\
\hline 3. & Klausa & P:“Peduli amat setan" & $\begin{array}{l}2,17 \mathrm{~b}, 22,23,24 \mathrm{a}, 46 \\
48,55,60\end{array}$ & 9 \\
\hline
\end{tabular}

\section{1) Kata}

Kata dasar merupakan satuan bahasa terkecil yang memiliki makna. Kata tersebut belum mengalami penambahan atau perubahan bentuk yang mengakibatkan perubahan makna. Berikut ini disajikan data $\{(04$ dan $10 \mathrm{~b})\}$ yang termasuk sarkasme berbentuk kata.

Nomor Data: (04)/Mar/2020

p : "Wifinya kok susah ya, biasanya kalau di lantai 2 cepet". 


UAD MIMESIS
Universitas
Ahmad Dahlan

q : "Heleh, miskin banget sih ngandelin wifi".

Tuturan di atas merupakan wujud sarkasme dalam bentuk kata dasar miskin. Kata miskin ialah orang yang serba kekurangan. Tuturan di atas disamakan seperti orang yang miskin yaitu orang yang hanya mengandalkan akses wifi gratis tanpa modal kouta sendiri.

\section{2) Frasa}

Frasa merupakan gabungan dua kata atau lebih yang bersifat nonpredikatif. Frasa yang membentuk sarkasme digolongkan menjadi dua yaitu frasa dasar plus makian dan frasa makian plus mu. Berikut ini disajikan data (20 dan 30) yang termasuk sarkasme berbentuk frasa.

Frasa Dasar Plus Makian

Nomor Data: (20)/Mar/2020

p : "Eh lu, dipanggilin dari tadi kagak denger po?"

q : "Kagak, aku pake headset soalnya".

$\mathrm{p}$ : "Dasar budeg"

Tuturan di atas termasuk sarkasme berbentuk frasa dasar plus makian berupa frasa dasar budeg yang dilontarkan oleh santri Persada.

Frasa Makian Plus $m u$

Nomor Data: (30)/Mar/2020

p : "Ayok makan mie nyinyir."

q : "Ngapain makan itu, lambemu udah lebih nyinyir."

Tuturan di atas termasuk sarkasme berbentuk frasa makian plus mu berupa frasa bagian tubuh yaitu lambe atau bibir yang diberi tambahan mu. Frasa lambemu termasuk bentuk sarkasme yang tidak pantas jika dilontarkan oleh santri Persada.

\section{3) Klausa}

Sarkasme yang berbentuk klausa pada umumnya ditambahkan pronominal di belakang makian dari berbagai referensi itu sendiri. Berikut ini disajikan data (55 dan 60) yang termasuk sarkasme berbentuk klausa.

Nomor Data: (55)/Mei/2020

p : "Fuckyou bitch"

Pada data di atas termasuk sarkasme berbentuk klausa. Fuckyou bitch berasal dari bahasa Inggris yang jika diartikan 'sialan kamu jalang'. Klausa Fuckyou bitch dilontarkan sebagai umpatan. Klausa Fuckyou bitch tidak pantas dilontarkan oleh santri persada.

\section{d. Pengunaan Sarkasme Berdasarkan Isi Tuturan}

Pemakaian bentuk sarkasme dalam penelitian ini dibagi menjadi tujuh, yaitu kata yang mengandung kapahitan, celaan getir, ungkapan kemarahan, umpatan, kata yang kurang enak di dengar, cemoohan, dan ragam sosial khusus. Berikut akan dipaparkan penggunaan bentuk sarkasme santri Persada UAD 2019/2020.

Tabel 2. Bentuk Sarkasme Berdasarkan Isi Tuturan

\begin{tabular}{|l|l|l|l|l|}
\hline No & $\begin{array}{l}\text { Bentuk } \\
\text { Sarkasme }\end{array}$ & Contoh Data & Kode Data & $\begin{array}{l}\text { Jumlah } \\
\text { Data yang } \\
\text { ditemukan }\end{array}$ \\
\hline 1. & $\begin{array}{l}\text { Kata yang } \\
\text { mengandung } \\
\text { kepahita }\end{array}$ & $\begin{array}{l}\text { p:"Kesel banget aku sama ulet betina" } \\
\text { q :Ya udah ngga usah diurusin aja" }\end{array}$ & $\begin{array}{l}13 \mathrm{a}, 17 \mathrm{a}, 24 \mathrm{a}, \\
28 \mathrm{a}, 29,30,41, \\
42,59,60,62 .\end{array}$ & 11 \\
\hline
\end{tabular}




\begin{tabular}{l} 
UAD \\
Universitas \\
Ahmad Dahlan \\
VOL. 3. No. 1, Januari 2022 \\
\hline
\end{tabular}

\begin{tabular}{|c|c|c|c|c|}
\hline 2 & Celaan getir & $\begin{array}{l}\mathrm{p}: \text { "Badanmu kok kurus kerontang } \\
\text { sih." q : "Aku udah makan banyak juga } \\
\text { tetep segini." }\end{array}$ & $\begin{array}{l}1,2,3,4,5,6,7, \\
8,9,10 \mathrm{a}, 13,15 \mathrm{~b}, 1 \\
6,20,21,24,25,26 \\
, 27,29,30,34,35, \\
36,37,38,39,40,4 \\
2,47,48,54,56,60\end{array}$ & 34 \\
\hline 3 & $\begin{array}{l}\text { Ungkapan } \\
\text { kemarahan }\end{array}$ & p : "Udeh sih lu kagak usah sok suci." & $\begin{array}{l}3,6,7,9,13,10 \mathrm{a} \\
15 \mathrm{a}, 16,17 \mathrm{a}, \\
17 \mathrm{~b}, 18,20,25, \\
28 \mathrm{a}, 29 \mathrm{a}, 38,40,4 \\
1,42,46,47, \\
53,54,62 .\end{array}$ & 24 \\
\hline 4 & Umpatan & $\begin{array}{l}\text { p:"Bangke emang dia tuh" q :"Lha kok } \\
\text { bisa, kenapa?" }\end{array}$ & $\begin{array}{l}3,6,10 \mathrm{~b}, 12,14 \\
, 23,24 \mathrm{~b}, 28 \mathrm{~b}, \\
31 \mathrm{~b}, 32,33,37, \\
41,43,44,45, \\
49,50,51,52, \\
55,56,57,58, \\
59,61,63 .\end{array}$ & 27 \\
\hline 5 & $\begin{array}{ll}\text { Kata } & \text { yang } \\
\text { kurang } & \text { enak } \\
\text { didengar } & \end{array}$ & $\begin{array}{l}\text { p:"Wifinya kok susah ya, biasanya } \\
\text { kalau di lantai } 2 \text { cepet." } \\
\text { q:"Heleh, miskin banget sih ngandelin } \\
\text { wifi." }\end{array}$ & $\begin{array}{l}1,4,10 \mathrm{a}, 11,15 \mathrm{~b}, 1 \\
8,19,22,26,27,31 \\
, 32,36,37 \\
, 44,45,54\end{array}$ & 17 \\
\hline 6 & Cemoohan & $\begin{array}{l}\mathrm{p} \text { : "Dia udah semester berapa?." } \\
\text { q : "Udah semester tua." p :"Kok } \\
\text { belum lulus sih?" } \\
\text { q : "Mau jadi penghuni tetap kali." }\end{array}$ & $\begin{array}{l}1,2,4,11,13,20,2 \\
2,24,25,26,27,30 \\
, 34,35,37,38,39, \\
40,42,44,45,47,4 \\
8,53 .\end{array}$ & 24 \\
\hline 7 & $\begin{array}{l}\text { Ragam sosial } \\
\text { khusus }\end{array}$ & $\begin{array}{l}\text { p : "Tiap hari ada aja yang ilang. Pasang } \\
\text { CCTV aja napa biar ketahuan } \\
\text { pencurinya." } \\
\text { q: "Iya siapa sih yang suka nyolongan" }\end{array}$ & $\begin{array}{l}7,9,18,21,29,42 \\
61\end{array}$ & 7 \\
\hline
\end{tabular}

\section{e. Kata yang Mengandung Kepahitan}

Salah satu bentuk tuturan sarkasme ialah bicara dengan kepahitan. Kata yang mengandung kepahitan dilatarbelakangi oleh tuturan yang menyinggung orang lain dan terdengar memakimaki. Berikut ini disajikan data (13), yang termasuk dalam kata yang mengandung kepahitan yang dilontarkan santri Persada UAD 2019/2020.

Data 13/Mar/2020

p : "Kesel banget aku sama ulet betina."

q : "Ya udah nggak usah diurusin aja"

Pada data di atas terdapat bentuk sarkasme berupa frasa ulet betina yang dilontarkan santri Persada saat membicarakan seorang wanita yang telah menggoda dan merebut kekasihnya. Ulet betina menjadi perumpamaan untuk wanita gatel yang suka menggoda dan mendekati laki-laki yang telah memiliki pasangan. Sifat wanita gatel diibaratkan seperti ulat betina yang menyebabkan gatal-gatal jika terkena bulunya. Bentuk sarkasme ulet betina memiliki fungsi sarkasme sebagai bentuk pernyataan persamaan antara sifat manusia yang 
sama seperti hewan berjenis ulat. Pada data ini tampak bahwa tuturan yang digunakan mengandung unsur berbicara dengan kepahitan karena menyamakan sifat manusia seperti hewan dan menyinggung perasaan orang lain.

Tabel 3. Faktor Penyebab Santri Melontarkan Sarkasme

\begin{tabular}{|c|c|c|c|c|}
\hline No & $\begin{array}{l}\text { Faktor } \\
\text { Penyebab }\end{array}$ & Contoh Data & Kode Data & $\begin{array}{l}\text { Jumlah } \\
\text { Data yang } \\
\text { Ditemukan }\end{array}$ \\
\hline 1 & $\begin{array}{l}\text { Latar belakang } \\
\text { pergaulan }\end{array}$ & $\begin{array}{l}\text { p:"Anjay, gue kalah main game” } \\
\text { q:"Hahaha, lebih jago gue ya."” }\end{array}$ & $\begin{array}{l}2,3,6,7,9,10,12, \\
14,19,21,31,32, \\
33,36,37,39,41, \\
43,50,51,52,54, \\
57,58,59,60,61, \\
63\end{array}$ & 28 \\
\hline 2 & Kebiasaan & $\begin{array}{l}\text { p:"Bantu bangunin yanglainnya } c u k \text {, } \\
\text { anjing." }\end{array}$ & $\begin{array}{l}2,3,6,14,19,31 \\
32,33,36,43,49 \\
50,51,52,54,55 \\
57,58,59,61,63\end{array}$ & 21 \\
\hline 3 & Reflek & $\begin{array}{l}\text { p:“Bego banget yang baca maps." } \\
\text { q:“Kampret. Bukan aku yang salah. } \\
\text { Mapsnya ini." }\end{array}$ & $\begin{array}{l}8,10,14,19,20 \\
24,31,32,33,41 \\
49,50,52,57,58 \\
59,61,63\end{array}$ & 18 \\
\hline 4 & Marah & $\begin{array}{l}\text { p:"Ada yang kebawa jilbab item nggak } \\
\text { ya?" q:“Aku nggak liat tuh" } \\
\text { p : "Siapa sih yang suka ngutil. Sebel." }\end{array}$ & $\begin{array}{l}3,6,7,9,13,10 \mathrm{a}, \\
15 \mathrm{a}, 16,17 \mathrm{a}, 17 \mathrm{~b}, \\
18,20,25,28 \mathrm{a}, \\
29 \mathrm{a}, 38,40,41 \\
42,46,47,53,54 \\
62 .\end{array}$ & 24 \\
\hline 5 & $\begin{array}{lr}\text { Tempat } & \text { dan } \\
\text { Waktu tidak } \\
\text { tepat }\end{array}$ & $\begin{array}{l}\text { P:“Cuk, mau ke mana?" } \\
\text { q : "Mau ke kampus, ntar siang balik ke } \\
\text { Persada lagi." }\end{array}$ & $\begin{array}{l}3,6,7,9,12,14,19, \\
21,29,31,32,33, \\
41,43,44,45,50, \\
51,54,55,57,58, \\
59,60,61\end{array}$ & 25 \\
\hline 6 & $\begin{array}{l}\text { Partisipan tidak } \\
\text { tepat }\end{array}$ & $\begin{array}{l}\text { p : "Eh lu dipanggilin daritadi kagak } \\
\text { denger po?" } \\
\text { q : "Kagak, aku pake headset soalnya." } \\
\text { p:"Dasar budeg }\end{array}$ & $\begin{array}{l}2,10,20,31,32 \\
37,41,45\end{array}$ & 8 \\
\hline 7 & $\begin{array}{lr}\text { Tujuan } & \text { tidak } \\
\text { sesuai } & \text { dengan } \\
\text { penutur } & \\
\end{array}$ & $\begin{array}{l}\text { p : "Gitu aja kagak bisa lu. Tolol bet } \\
\text { dah." } \\
\text { q : "Iya gue nggak dong" }\end{array}$ & $\begin{array}{l}2,4,10,11,20,31 \\
37,40,41,45,47\end{array}$ & 10 \\
\hline 8 & $\begin{array}{l}\text { Nada saat } \\
\text { menyampaikan } \\
\text { pesan } \\
\text { (mengejek dan } \\
\text { kasar) }\end{array}$ & $\begin{array}{l}\text { p:"Bantu bangunin yang lainnya } c u k \text {, } \\
\text { anjing." }\end{array}$ & $\begin{array}{l}1,3,5,6,7,8,9,10, \\
13,14,20,24,26, \\
27,28,29,30,31, \\
32,33,37,38,41, \\
43,44,45,50,51, \\
53,54,55,56,57, \\
58,59,60,61\end{array}$ & 37 \\
\hline 9 & $\begin{array}{l}\text { Media Bahasa } \\
\text { (lisan/tulisan) }\end{array}$ & $\begin{array}{l}\text { Lisan: p : "Tau nggak siapa yang } \\
\text { kepergok semalam?" q : "nggak tau, } \\
\text { emang siapa?" p: "Si itulah, siapa lagi" }\end{array}$ & $\begin{array}{l}\text { Lisan: } \\
1,2,3,4,5,6,7,8,9 \\
10,11,13,14,19\end{array}$ & 63 \\
\hline
\end{tabular}




MIMESIS
Universitas
Ahmad Dahlan
VOL. 3o. 1, Januari 2022

\begin{tabular}{|l|l|l|l|l|}
\hline & & q : "Etdah, lemes bener mulutmu." & $20,22,23,24,25$, & \\
& & Tulisan: p : "Cekek online & $26,27,28,29,30$, & \\
& & $31,32,33,37,38$, & \\
& & & $41,43,44,45,50$, & \\
& & & $51,53,54,55,56$, & \\
& & & $57,58,59,60,61$. & \\
& & & Tulisan: & \\
& & & $12,15,16,17,18$, & \\
& & & $21,34,35,36,39$, & \\
& & & $40,42,46,47,48$, & \\
& & & $49,52,62,63$. & \\
& Norma dalam & p : "Cekek online" & $1,4,6,7,9,10,19$, & 29 \\
& berinteraksi & & $20,22,24,31,32$, & \\
& & & $33,37,40,41,43$, & \\
& & & $44,45,50,51,54$, & \\
& & & $55,56,57,58,59$, & \\
& & & $60,61$. & \\
\hline
\end{tabular}

\section{f. Latar Belakang Pergaulan}

Faktor penyebab santri melontarkan sarkasme setelah dilakukan wawancara, salah satu penyebabnya adalah latar belakang pergaulan sebelumnya. Faktor lingkungan dan daerah asal santri menjadi faktor yang menyebabkan santri melontarkan sarkasme di lingkungan Persada UAD. Berikut ini disajikan data (14) dan (19) yang dilontarkan oleh santri Persada UAD 2019/2020 sebagai berikut.

Data 14/Mar/2020

p : "Anjay, gue kalah main game."

q : "Hahaha, lebih jago gue ya."

Pada data di atas terdapat bentuk sarkasme kata anjay yang dilontarkan oleh santri Persada UAD secara spontan saat kalah dalam sebuah permainan. Kata anjay yang dilontarkan berasal dari kata-kata yang biasa diucapkan saat di sekolah dulu dan masih terbawa hingga di Persada. Kata anjay seharusnya tidak perlu dilontarkan di Persada yang identik dengan nuansa islami. Sebagai santri juga harus meminimalisir penggunaan kata tersebut.

\section{KESIMPULAN}

Hasil penelitian menunjukkan bahwa penggunaan bentuk sarkasme di kalangan santri Persada UAD tahun 2019/2020 berdasarkan gramatikal ditemukan sebanyak 70 bentuk sarkasme berdasarkan gramatikal Bentuk sarkasme secara gramatikal terdiri dari kata, frasa, dan klausa. Bentuk sarkasme secara gramatikal yang paling dominan berbentuk kata dan yang paling sedikit berbentuk klausa. Penggunaan bentuk sarkasme di kalangan santri Persada UAD tahun 2019/2020 berdasarkan isi tuturan ditemukan sebanyak 144 data dalam 63 peristiwa tutur bentuk sarkasme berdasarkan isi tuturan terdiri dari 7 bentuk sarkasme yaitu kata yang mengandung kepahitan, celaan getir, ungkapan kemarahan, umpatan, kata yang kurang enak di dengar, cemoohan, dan ragam sosial khusus. Bentuk sarkasme berdasarkan isi tuturan yang 


\begin{tabular}{l} 
UADESIS \\
Universitas \\
Ahmad Dahlan \\
VOL. No. 1, Januari 2022 \\
\hline
\end{tabular}

dilontarkan santri Persada UAD 2019/2020 yang dominan yaitu celaan getir, sedangkan yang paling sedikit adalah ragam sosial khusus. Faktor penyebab santri pesantren Mahasiswa KH. Ahmad Dahlan (Persada) UAD tahun 2019/2020 melontarkan sarkasme ditemukan sebanyak 263 data dalam 63 peristiwa tutur berupa sepuluh faktor yaitu latar belakang pergaulan, kebiasaan, reflek, marah, tempat dan waktu tidak tepat, partisipan tidak tepat, tujuan tidak sesuai dengan penutur, nada saat menyampaikan pesan, media bahasa, dan norma dalam berinteraksi. Faktor penyebab santri Persada 2019/2020 melontarkan sarkasme ditemukan yang dominan yaitu nada yang digunakan dalam berinterksi dalam tuturan lisan, sedangkan faktor penyebab yang paling sedikit adalah partisipan tidak tepat.

\section{DAFTAR PUSTAKA}

Halliday, M. (2004). An Introduction to Functional Grammar (4 ed.). New York: Oxford University Press.

Halliday, M., \& Matthiessen, M. (2014). Halliday's Introduction to Functional Grammar (4 ed.). New York: Hodder Arnold.

Fairclough, N. (1995). Critical Discourse Analysis: The Critical Study of Language. London: Longman Group Limited.

Dijk, T. V. (2004). Critical Discourse Analysis. In D. Schriffin, D. Tannen, \& H. E. Hamilton, The Book of Discourse Analysis (pp. 352-371). Oxford: Blackwell.

Silaswati, D. (2019). Analisis Wacana Kritis Dalam Pengkajian Wacana. METAMORFOSIS: Jurnal Bahasa, Sastra Indonesia dan Pengajarannya, 12(1), 1-10.

Paltridge, B. (2012). Discourse Analysis: An Introduction. London and New York: Bloomsburry Academic.

Jorgensen, M., \& Phillips, L. J. (2002). Discourse Analysis as Theory and Method. London: Sage Publications.

Rumata, V. M., \& Elfrida, S. V. (2019). Ideologi dan Kekuasaan Pemerintah di Balik Wacana Pembangunan Tol Laut - Analisis Wacana Kritis Terhadap Materi Siaran DBU LPP RRI Sorong, 20 Oktober 2017. Jurnal Penelitian Komunikasi dan Opini Publik, 23(2), 90-103.

Anggito, A., \& Setiawan, J. (2018). Metodologi Penelitian Kualitatif. Jawa Barat: CV. Jejak.

Suswandi, I. (2020). Representasi Kelugasan Beranda Laman www.covid-19.go.id: Tinjauan Analisis Wacana Kritis. Mimesis, 1(2), 21-43.

Wiratno, T. (2018). Pengantar Ringkas Linguistik Sistemik Fungsional. Yogyakarta: Pustaka Pelajar.

CNNIndonesia. (2021). Isi Maklumat Kapolri tentang Larang Simbol FPI di Masyarakat. Retrieved January 6, 2021, from https://www.cnnindonesia.com/nasional/20210101110207-12588432/isi-maklumat-kapolri-tentang-larang-simbol-fpi-di-masyarakat.

BBCNews Indonesia. (2021). Pemerintah larang kegiatan FPI, polisi larang masyarakat unggah dan sebarkan konten terkait FPI. Retrieved Januari 5, 2021, from https://www.bbc.com/indonesia/indonesia-55481350.

Chaer, A. (1994). Linguistik Umum. Jakarta: Rineka Cipta.

Alwi, H. (1992). Modalitas dalam Bahasa Indonesia. Yogyakarta: Kanisius.

Eggins, S. (2004). An Introduction to Systemic Functional Linguistics (2 ed.). New York: Continuum.

Eriyanto. (2001). Analisis Wacana: Pengantar Analisis Teks Media. Yogyakarta: LKiS.

Martin, J., Matthiessen, C., \& Painter, C. (1997). Working with Functional Grammar. London: Arnold.

Saragih, A. (2007). Fungsi Tekstual dalam Wacana: Panduan Menulis Rema dan Tema. Medan: Balai Bahasa.

Bloor, T., \& Bloor, M. (2004). The Functional Analysis of English: A Hallidayan Approach. London: Arnold.

Fairclough, N. (2013). Critical Discourse Analysis: The Critical Study of Language (2 ed.). London: Routledge. 
Tempo.co. (2021). UU Ormas Dasar Pembubaran FPI Bermasalah karena Hilangkan Mekanisme Peradilan. Retrieved January 6, 2021, from https://nasional.tempo.co/read/1418960/uu-ormasdasar-pembubaran-fpi-bermasalah-karena-hilangkan-mekanisme-peradilan/full\&view $=$ ok .

Wodak, R., \& Meyer, M. (2008). Methods of Critical Discourse Analysis (2 ed.). London and Canada: Sage Publishing.

Fairclough, N. (2002). The dialectics of discourse. TEXTUS, 14(2), 3-10. Retrieved from http://www.ling.lancs

Halliday, M., \& Matthiessen, M. (2004). Halliday's Introduction to Functional Grammar (3 ed.). UK: Hodder Education.

KompasTV. (2020). FPI Dilarang, Ini 7 Poin Larangan dari Pemerintah Indonesia. Retrieved December 26, 2020, from https://www.kompas.tv/article/134178/fpi-dilarang-ini-7-poinlarangan-dari-pemerintah-indonesia.

Wiratno, T., \& Santoso, R. (2011). Pengantar Linguistik Umum. Tangerang Selatan: Universitas Terbuka. 